\title{
Is narrow qrs complex tachyarrythmia always from supraventricular?
}

Tiya Setiadi, Hauda El Rasyid

Department of Cardiology and Vascular Medicine, Faculty of Medicine, Universitas Andalas

Correspondence: Tiya Setiadi; email: tiyasetiadi@hotmail.com

\begin{abstract}
Idiopathic left ventricular tachycardia (previously known as fascicular VT) is characterized by right bundle branch block (RBBB) left axis ventricular tachycardia (VT) with a relatively narrow QRS (120$140 \mathrm{~ms}$ ) in young patients and sensitive to verapamil. Objective: To remind that not all tachyarrhythmias with relatively narrow QRS are derived from supraventricular. Cases: First case of 23 years old man with chief complain palpitation and presyncope with narrow QRS ventricular tachycardia electrocardiography (ECG). Second case of 16 years old man with chief complain palpitation with narrow QRS ventricular tachycardia ECG, both of them are getting better after administration of diltiazem and verapamil. Conclusion: Idiopathic left ventricular tachycardia is associated with presyncope, palpitation and was successfully terminated with verapamil. Medical management is variable in its outcomes and given the age of the population affected. Narrow QRS complex tachycardia not always from supraventricular, we should think about ventricular tachycardia especially ILVT if there is no structural heart disease.
\end{abstract}

Keywords: ILVT; ventricular tachycardia; supraventricular

\section{INTRODUCTION}

It is understood that Ventricular Tachycardia (VT) characterized by tachyarrhythmias with a wide QRS complex (>140 ms) and other VT conditions. In some cases of VT, the QRS complex is not so wide (120-140 ms), often misinterpreted as a Supraventricular Arrhythmia (SVT). ${ }^{1}$ Idiopathic Fascicular Left Ventricular Tachycardia (ILVT) is characterized by VT with Right Bundle Branch Block (RBBB) left axis or right axis VT. ILVT typically affects young males aged 15-40 years without any structural heart disease. $^{2}$ Misdiagnosis of ILVT with SVT often results in untreated tachyarrhythmias. ILVT represents 10-15\% of all idiopathic left ventricular tachycardia seen in clinical practice today Induction may be facilitated by isoproterenol or atropine, or a bolus of intravenous calcium chloride. In 1981, Belhassen et al. demonstrated that intravenous administration of verapamil significantly decreased the recurrence rate of ILVT in afflicted patients. ${ }^{3}$ This paper aims to remind that not all tachyarrhythmias with relatively narrow QRS are derived from supraventricular. 


\section{CASE REPORT}

\section{First Case}

A 23 years old man came to dr. M. Djamil Emergency Department (ED) with chief complain presyncope. He felt palpitation since 1 days ago. He felt recurrent palpitation \& presyncope since 2 month ago. He already felt recurrent palpitation and presyncope since he was a child, but spontaneously recovered after several minutes. He denied shortness of breath nor chest pain.
At ED he looked fully alert. His blood pressure was $95 / 65 \mathrm{mmHg}$, heart rate 200 beats per minute, respiratory rate 24 times per minute, and temperature was $36.8^{\circ} \mathrm{C}$. Jugular venous pressure was $5+2 \mathrm{cmH}_{2} \mathrm{O}$. He had normal BMI $25 \mathrm{~kg} / \mathrm{m}^{2}$. Cardiac auscultation found normal first and second heart sound, no murmur. Lung auscultation found vesicular sound, no rales and wheezing. Abdomen and extremity examination were unremarkable. He had already performed Holter monitoring with the result no rhythm disturbance and T inverted at II, III, aVF, V4-V6.

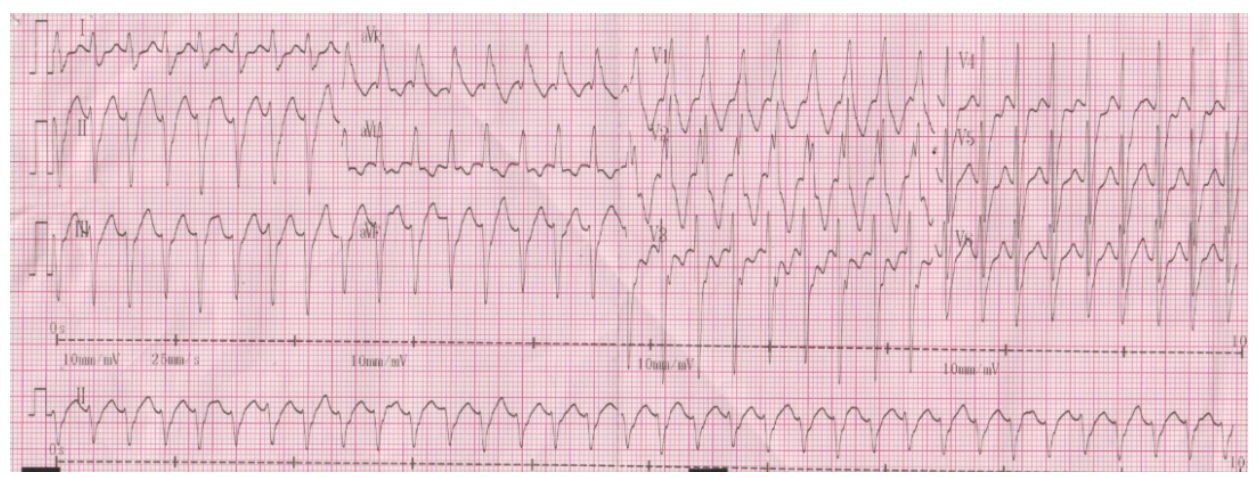

Figure 1. 12-lead ECG at ED M. Djamil Hospital

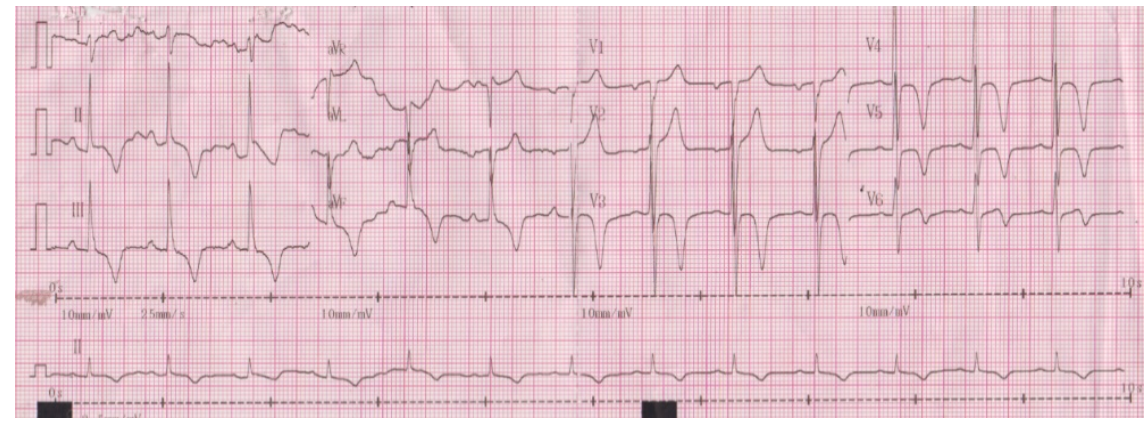

Figure 2. Post-termination with Diltiazem

A 12-lead ECG showed regular, narrow complex tachyarrhythmia with HR 200 bpm, RBBB pattern, and LAD axis (Figure 1). Hemoglobin was $15.9 \mathrm{mg} / \mathrm{dL}$, Leucocyte $9,030 / \mathrm{mm}^{3}$, Haematocrit 44\%, Platelet 319,000/mm³ , Random Blood Glucose 103 $\mathrm{mg} / \mathrm{dL}$, Natrium $139 \mathrm{mmol} / \mathrm{L}$, Kalium 4.0 $\mathrm{mmol} / \mathrm{L}$, Chloride $105 \mathrm{mmol} / \mathrm{l}$, Calcium 9.6 $\mathrm{mmol} / \mathrm{L}$, Urea $30 \mathrm{mg} / \mathrm{dL}, \mathrm{Cr} 1.2 \mathrm{mg} / \mathrm{dL}, \mathrm{CCT}$ $79 \mathrm{~mL} / \mathrm{min}$, CKMB $11 \mu / L$, Trop $T<0.03 \mu / L$. Chest radiography demonstrated cardiomegaly (CTR 50\%), normal aorta and 
pulmonal segment, normal pulmonary vascular marking there was infiltrate at lung field.

The diagnosis was SVT AV-nodal re-entry tachycardia (AVNRT) with aberrancy. The treatments were given 2-4 litres of oxygen by nasal cannula, and diltiazem $20 \mathrm{mg}$ bolus iv within 2 minutes after failed vagal maneuver. After we gave diltiazem bolus, tachyarrhythmia becomes terminated and returned to sinus rhythm, T inverted at II, III, aVF, V3-V6 (Figure 2).

Patient was moved to cardiology ward and therapy was continued with verapamil 2x80 mg tab and lansoprazole. Patient was planned to perform angiography because of there was deep $T$ wave inversion symmetrically. The result of angiography was normal.

At the third day, patient was stable without palpitation, and discharged with therapy verapamil $2 \times 80 \mathrm{mg}$ tab and lansoprazole $1 \times 30 \mathrm{mg}$ tab. Patient controlled to outpatient clinic routinely, but he still felt palpitation and presyncope. Patient was planned to electrophysiology (EP) study.

At May $25^{\text {th }}, 2017$, patient was performed electrophysiology study. At ward, a 12-lead ECG before EP study showed sinus rhythm,
QRS rate $68 \mathrm{x} / \mathrm{min}$, without ST-T changes. From the EP study, pacing at RV from 500$350 \mathrm{~ms}$, there was VA dissociation with rate A 550 ms. Sustained VT was induced by pacing at Right Ventricular Outflow Tract (RVOT) with ECG morphology narrow QRS complex, RBBB and Left Axis Deviation. Electrograms (EGM) showed that rate at $\mathrm{RV}(370 \mathrm{~ms})$ faster than rate at A (atrium) (580 ms) with earliest at RV. It was indicated VT and terminated by overdriven from RV. Procedure was stopped because of technical problem. The result of EP study was ILVT left posterior with bifascicular block. Patient got therapy verapamil $3 \times 80 \mathrm{mg}$ and controlled routinely to outpatient clinic.

\section{Second Case}

A 16 years old man came to dr. M. Djamil Emergency Department (ED) with chief complain palpitation. He felt palpitation since 7 hours before admission. He felt recurrent palpitation since 2 years ago but the symptom didn't happen frequently. He already hospitalized at Reksodiwiryo Hospital with same complaint, but he forgot the therapy and he didn't control routinely. He denied shortness of breath nor chest pain.

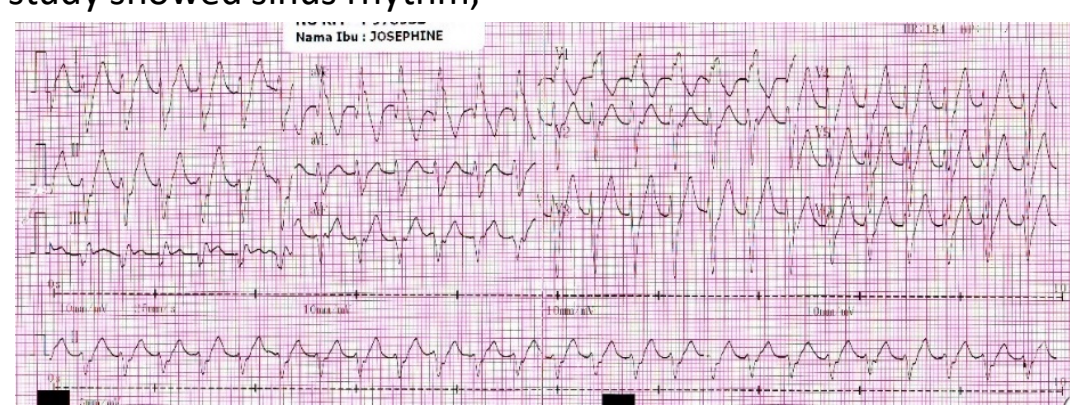

Figure 3. 12-lead ECG at ED M.Djamil Hospital (second patient) 
At ED he looked fully alert. His blood pressure was $125 / 58 \mathrm{mmHg}$, heart rate 154 beats per minute, respiratory rate 24 times per minute, and temperature was $37.1^{\circ} \mathrm{C}$. Jugular venous pressure was $5+2$ $\mathrm{cmH}_{2} \mathrm{O}$. He had normal BMI $25 \mathrm{~kg} / \mathrm{m}^{2}$.
Cardiac auscultation found normal first and second heart sound, no murmur. Lung auscultation found vesicular sound, no rales and wheezing. Abdomen and extremity examination were unremarkable.

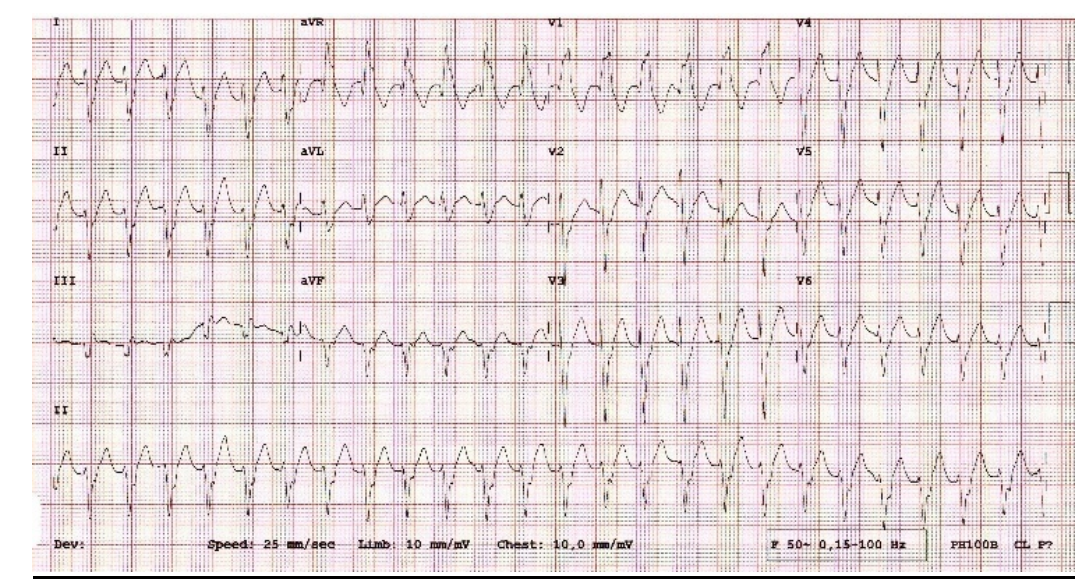

Figure 4. ECG patient on ward

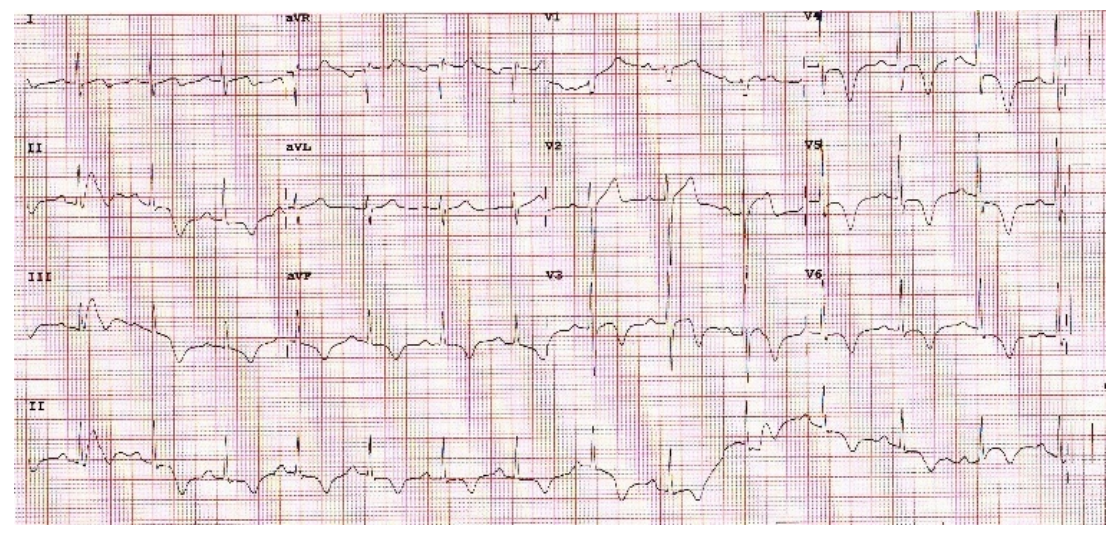

Figure 5. Post-termination with Verapamil oral

A 12-lead ECG showed regular, narrow complex (QRS complex $120 \mathrm{~ms}$ ) tachyarrhythmia with HR 154 bpm (Figure 3). Hemoglobin was $15.6 \mathrm{mg} / \mathrm{dL}$, Leucocyte $8,930 / \mathrm{mm}^{3}$, Haematocrit 47\%, Platelet $274,000 / \mathrm{mm}^{3}$, Random Blood Glucose 80 $\mathrm{mg} / \mathrm{dL}$, Natrium $140 \mathrm{mmol} / \mathrm{L}$, Kalium 4.2 $\mathrm{mmol} / \mathrm{L}$, Chloride $107 \mathrm{mmol} / \mathrm{L}$, Calcium 9.6 $\mathrm{mmol} / \mathrm{L}$, Urea $20 \mathrm{mg} / \mathrm{dL}, \mathrm{Cr} 0.7 \mathrm{mg} / \mathrm{dL}, \mathrm{CCT}$ $172 \mathrm{~mL} / \mathrm{min}$.
Chest radiography demonstrated cardiomegaly (CTR 50\%), normal aorta and pulmonal segment, normal pulmonary vascular. There was infiltrate at lung field.

The diagnosis was SVT with aberrancy. The treatments were given 2-4 litres of oxygen by nasal cannula, and diltiazem bolus 20 mg after failed vagal maneuver, but the ECG didn't convert so we gave rebolus diltiazem $20 \mathrm{mg}$ and continued with maintenance drip of diltiazem $5 \mathrm{mg} /$ hour. 
Patient was planned move to CVCU but it was full so patient move to ward.

At 2nd day, patient haemodynamic was stable, the ECG still showed ventricular tachycardia (Figure 4). The therapy was changed from diltiazem maintenance to amiodarone. But the rhythm didn't convert. Amiodarone was stopped and changed into verapamil $3 \times 80 \mathrm{mg}$ and the rhythm was returned to normal and $T$ inverted at II, III, aVF, V3-V6 (Figure 5). The patient was diagnosed suspect ILVT. After 2 days observation and mobilization on ward, patient was discharged with therapy verapamil $3 \times 80 \mathrm{mg}$. Patient was planned to ablation from the outpatient clinic.

\section{DISCUSSIONS}

Sustained monomorphic VT is most often related to myocardial structure heart disease, including healed myocardial infarction and cardiomyopathies. However, no apparent structural abnormality is identified in about $10 \%$ of all sustained monomorphic VTs in the United States and $20 \%$ of those in Japan. ${ }^{1}$ These VTs are referred to as "idiopathic." Idiopathic VTs usually occur in specific locations and have specific QRS morphologies, whereas VTs associated with structural heart disease have a QRS morphology that tends to indicate the location of the scar. Idiopathic VT comprises multiple discrete subtypes that are best differentiated by their mechanism, QRS morphology, and site of origin. ILVT represents $10-15 \%$ of all idiopathic left ventricular tachycardia seen in clinical practice today. ${ }^{4}$ This arrhythmia was first described by Zipes et al. in 1979, when they reported three cases of RBBB left axis VT with a relatively narrow QRS $(120-140 \mathrm{~ms})$ in young patients. ${ }^{5}$

Table 1. Classification of ILVT relative to the mechanism. ${ }^{6}$
I. Verapamil-sensitive VT (re-entry)
II. Adenosine-sensitive VT (triggered activity)
III. Propranolol-sensitive VT (automaticity)

Table 2. Classification of ILVT relative to the site of origin. ${ }^{6}$

I. Verapamil-sensitive fascicular VT (reentry)

Left posterior fascicular VT
Proximal type (mid-septum)
Distal type (apical inferior
septum)
Left anterior fascicular VT
Proximal type (mid-septum)
Distal type (anterolateral wall)
Left upper septal fascicular VT
(upper septum)

II. Focal Purkinje VT (triggered activity or automaticity)

III. Mitral annular VT (triggered activity, reentry, or automaticity)

IV. Left outflow tract VT (triggered activity, reentry, or automaticity)

Endocardial origin Medio superior aspect of mitral annulus (aortomitral continuity) Superior basal septum (His bundle area)

Epicardial origin

Aortic sinus approach

Coronary venous approach

Pulmonary artery approach Direct epicardial approach

Verapamil-sensitive fascicular VT is the most common form of idiopathic left VT. It was first recognized as an electrocardiographic entity in 1979 by Zipes and colleagues, who identified the 
characteristic diagnostic triad: (1) induction with atrial pacing; (2) right bundle branch block (RBBB) and left-axis configuration; and (3) manifestation in patients without structural heart disease. ${ }^{5}$ ILVT has been classified into three subgroups relative to the mechanism (Table 1) and also classified idiopathic VT according to its site of origin (Table 2 ). ${ }^{6}$

ILVT typically presents in young adults (15 to 40 years) and mainly affects males (60$80 \%$ ). The most frequent clinical presentation is paroxysmal episodes of palpitations, dizziness and, less frequently, syncope. Tachycardiomyopathy has been described in the $6 \%$ of cases as a result of persistent tachycardia and usually reversible after successful ablation. Although most episodes occur at rest, exercise, emotional stress and catecholamine infusion can act as triggers. ${ }^{7,8}$

Generally, the event experienced by the patient while at rest, it episodes usually occur at rest. Although triggered activity was at first postulated as a potential mechanism, later studies showed that ILVT behaves electrophysiologically as a reentrant tachycardia. In the most common form, posterior ILVT, the re-entrant circuit extends from the basal to the mid-apical region of the interventricular septum. The entrance to the circuit is in the basal interventricular septum. From there, the wave front spreads in an apical direction along the so-called antegrade arm. It has been suggested that it could be formed by abnormal Purkinje fibbers since it shows decremental properties, and sensitivity to verapamil and constitutes the slow zone of the circuit. ${ }^{6,9,10}$

In this serial case, both of case show a range of their age is suitable with epidemiology data. First case, a man 23 years old and according to predominance of ILVT occurrence with recurrent palpitation and presyncope. At first time, patients and parents consider it is a normal palpitation, but this happen frequently 2 months before admission. It caused patients went to the doctor. It was also happened with patient in second case.

Quite often, the ILVT can be confused with a paroxysmal supraventricular tachycardia conducted with aberrancy because of its relatively narrow QRS, response to verapamil and presentation in young patients without structural heart disease. The presence of ventriculoarterial dissociation in the electrocardiogram or during the electrophysiological study may clarify the diagnosis. From the patient's ECG we found narrow QRS complex tachycardia, we diagnose patient with SVT based on its QRS morphology (narrow QRS complex $120 \mathrm{~ms}$, HR $200 \mathrm{x} /$ minutes). Then we gave patient diltiazem bolus and it was converted to sinus rhythm. There is an algorithm to differentiate it is SVT with aberrancy or VT. We can use Brugada or Vereckei algorithm, but this algorithm is approach to differential diagnosis of regular tachycardia with a wide QRS complex. ${ }^{11}$ Patient electrocardiography in first case was characterised by RBBB morphology and left axis suggesting it is 
posterior

fascicular

ventricular

tachycardia/ILVT. To make sure our ILVT diagnosis, we performed an echocardiography and the result is in normal limit. The baseline ECG after terminates is normal in most patient with ILVT though it may present T-wave inversion immediately after tachycardia (cardiac memory). ${ }^{7}$ Both of patients present $T$ wave inversion in a baseline ECG after tachycardia. In EP study, sustained VT was induced by pacing at RVOT with ECG morphology narrow QRS complex, RBBB and Left Axis Deviation. From the electrograms (EGM) showed that rate at RV (370 ms) faster than rate at A (atrium) (580 ms) with earliest at RV. It was illustrated a less likely an AVNRT, but it was possible a VT, AVRT or Atrial Tachycardia. The patient was diagnosed VT after we found VA dissociation with rate $A 550$ ms when pacing at RV (500-350 ms).

At the first time both of patients was diagnosed SVT AVNRT with aberrancy. As in other cases of wide QRS tachycardia, we should evaluate the hemodynamic status of the patient. According to AHA guideline management of SVT 2015, in acute stable condition we should perform vagal maneuver (Class I) but if it's fail, we could give adenosine (Class I). We couldn't give adenosine to patient because technical problem. Based on AHA guideline we could gave intravenous diltiazem or verapamil (Class Ila). ${ }^{10}$ In these cases the patient was treated by diltiazem bolus. At First patient, the rhythm converted to sinus rhythm. There was no doubt we diagnosed patient with SVT at that time, but we doubt about our first diagnosis, because after the rhythm back to normal we saw a deep inverted $\mathrm{T}$ wave like a cardiac memory pattern. So, we performed echocardiography and angiography, the result was normal, and we changed our diagnosis into ILVT after we performed EP study. At second patient after we gave intravenous diltiazem, the rhythm didn't convert to normal rhythm. We changed the therapy with amiodarone, but nothing was changed. We performed echocardiography, and it was normal. We thought it wasn't an ordinary narrow QRS complex tachycardia. Maybe it was ILVT. So, we planned to change therapy with verapamil oral $3 \times 80 \mathrm{mg}$ and it worked. The rhythm was back to normal and the baseline ECG was normal with deep T wave inversion.

In stable patients, first line treatment is verapamil. ${ }^{7}$ The intravenous administration of $10 \mathrm{mg}$ (given for over 1 minute) can interrupt this tachycardia due to its calcium-dependence. However, unlike other idiopathic ventricular tachycardia, ILVT usually does not respond to vagal manoeuvres, adenosine or beta-blockers, and first line therapy is verapamil. In a second case, the rhythm converted into sinus rhythm after we gave him verapamil $3 \times 80 \mathrm{mg}$. According to ESC guideline management of ventricular arrythmia 2015, we could give verapamil to ILVT patient with dosage $120-240 \mathrm{mg} /$ day. ${ }^{12}$

Verapamil may be helpful in patients with mild symptoms. When symptoms are 
severe and pharmacologic treatment is not effective or is poorly tolerated, catheter ablation is recommended. Ablation success rates as reported in various series vary between $85 \%$ and $95 \%$ and are generally higher in those patients with posterior IFLVT. Recurrence rates are also lower in these patients as well ( $5 \%$ vs $12.5 \%$ ). Although complications are rare, the most common one is the development of left bundle branch or atrioventricular block, transient in all reported cases. It is also possible to damage the aortic valve if retrograde aortic approach is performed or to damage the mitral valve in cases of transseptal puncture. ${ }^{7}$ Because ablation have a high success rate to cure this ILVT, we planned to perform ablation to both of patients.

\section{CONCLUSSIONS}

This case represents ILVT with palpitations. It was associated with presyncope and was successfully terminated with verapamil. ILVT continued to represent a common form of left ventricular tachycardia in patients with seemingly structurally normal hearts. Medical management is variable in its outcomes and given the age of the population affected, it is often difficult to ensure adherence. Narrow QRS complex tachycardia didn't always from supraventricular, we should think about ventricular tachycardia especially ILVT if there is no structural heart disease. ILVT should always be considered as differential for patients presenting with a regular right bundle branch tachycardia. With the current knowledge concerning the pathophysiology of the tachycardia and modern ablation techniques, ILVT has an excellent prognosis.

\section{ACKNOWLEDGEMENT}

The authors would like to thank Rika Permata Sari, MD who assisted the authors in manuscript preparation.

\section{REFERENCES}

1. Nogami A. Ablation of idiopathic Left Ventricular and Fascicular Tachycardias. In: Huang SKS, Wood MA, editor. Catheter Ablation of Cardiac Arrhythmias. $2^{\text {nd }}$ Ed. Philadelphia: Elsevier Saunders; 2011. p.463-85. doi: 10.1016/C2009-0-41618-0.

2. Kukar N, Sanghvi Neil. Idiopathic Fascicular Left Ventricular Tachycardia: Case Report and Review of the Literature. The Journal of Innovations in Cardiac Rhythm Management. 2014; 5:1700-4. [Abstract/FREE Full-Text].

3. Belhassen $\mathrm{B}$, Rotmensch $\mathrm{HH}$, Laniado $\mathrm{S}$. Response of recurrent sustained ventricular tachycardia to verapamil. Br Heart J. 1981; 46(6):679-82. doi: 10.1136/hrt.46.6.679. [PubMed] [PMC free article].

4. Lerman BB, Stein KM, Markowitz SM. Mechanisms of idiopathic left ventricular tachycardia. J Cardiovasc Electrophysiol. 1997; 8(5):571-82. doi: 10.1111/j.1540-8167.1997.tb00826.x. [PubMed]. 
5. Zipes DP, Foster PR, Troup PJ, Pedersen DH. Atrial induction of ventricular tachycardia: reentry versus triggered automaticity. Am J Cardiol. 1979; 44(1):1-8. doi: 10.1016/0002-9149(79)90242-x. [PubMed].

6. Nogami A. Idiopathic left ventricular tachycardia: assessment and treatment. Card Electrophysiol Rev. 2002; 6(4):448-57. doi: 10.1023/a:1021100828459. [PubMed].

7. Reviriego. Idiopathic fascicular left ventricular tachycardia. E-Journal of the ESC Council for Cardiology Practice [Internet]. 2010; 9(13). [Abstract/FREE full-text].

8. Brugada J, Diez DP. How to recognize and manage idiopathic ventricular tachycardia. E-Journal of Cardiology Practice ESC [Internet]. 2010; 8(26). [Abstract/FREE full-text].

9. Aiba T, Suyama K, Aihara N, Taguchi A, Shimizu W, Kurita T, et al. The role of Purkinje and prePurkinje potentials in the reentrant circuit of verapamil-sensitive idiopathic LV tachycardia. Pacing Clin Electrophysiol. 2001; 24(3):333-44. doi: 10.1046/j.1460-9592.2001.00333.x. [PubMed].

10. Tsuchiya T, Okumura K, Honda T, Iwasa A, Ashikaga K. Effects of verapamil and lidocaine on two components of the re-entry circuit of verapamil-senstitive idiopathic left ventricular tachycardia. J Am Coll Cardiol. 2001; 37(5):1415-21. doi: 10.1016/s0735-1097(01)01117-2. [PubMed].

11. Vereckei A. Current algorithms for the diagnosis of wide QRS complex tachycardias. Curr Cardiol Rev. 2014; 10(3):262-76. doi: 10.2174/1573403×10666140514103309. [PubMed] [PMC free article].

12. Priori SG, Blomström-Lundqvist C, Mazzanti A, Blom N, Borggrefe M, Camm J, et al. 2015 ESC Guidelines for the management of patients with ventricular arrhythmias and the prevention of sudden cardiac death: The Task Force for the Management of Patients with Ventricular Arrhythmias and the Prevention of Sudden Cardiac Death of the European Society of Cardiology (ESC). Endorsed by: Association for European Paediatric and Congenital Cardiology (AEPC). Eur Heart J. 2015; 36(41):2793-867. doi: 10.1093/eurheartj/ehv316. [PubMed]. 